\title{
Autonomous learning mode of college English
}

\author{
Zhao Hui Min ${ }^{1, a}$ \\ ${ }^{1}$ Bohai university, Jinzhou, 121013 China \\ ahmzhao2008@163.com
}

Keywords: Autonomous learning; Self-efficacy; College English teaching.

\begin{abstract}
The rapid development of economic society requires students to possess lifelong learning ability. Currently, college English teaching still stays in traditional mode and the autonomous learning ability of students is much low and students can not acquire knowledge independently. Therefore, it is the key point to cultivate the autonomous learning ability of students. In this article, the author defines the autonomous learning and autonomy, and discusses the corresponding strategies which are helpful in English teaching.
\end{abstract}

\section{Introduction}

College English Curriculum Requirements (for Trial Implementation) issued in 2004 points out that institutions of higher learning should adopt new teaching modes to improve traditional single-mode classroom teaching by fully making use of multimedia and network technologies. New teaching modes are expected to utilize modern information technologies, especially the network technology, to break the limitations of time and place of English teaching and develop it towards individualized and autonomous learning. Therefore, the primary task of college English teaching in the $21^{\text {st }}$ century is to teach students to learn autonomously and cultivate their independent learning abilities according to their individual differences in characteristics, interests, motivations, intelligences and learning strategies. It is an inevitable development trend of future education as well. Foreign language learning, as an independent acquisition process, requires learners to consciously adjust their cognitive means such as learning methods and strategies to finish learning tasks. Foreign languages learned by Chinese students and their native language belong to different language families. Cultural traditions and language features (including pronunciation, grammar and writing system) of foreign languages have great differences with those of the native language. The learning of foreign languages is far more difficult than the acquisition of the first language, so only learners with strong senses of autonomous learning can effectively learn foreign languages. Cohen, a famous linguistician, incisively points out that the success of language learning depends on learners themselves and learners' own factors as well as their abilities to making full use of learning opportunities. Teachers can only offer part of language inputs in class, while lots of learning and practice outside the classroom are an important guarantee for successful foreign language learning. The characteristic of foreign languages requires students to have strong autonomous learning ability. Autonomous learning is the key to language acquisition. Whether learners can successfully learn languages mainly depends on their autonomous leaning abilities.

Autonomous learning is an ability responsible for one's learning or a process or ability to manage the learning. It means that students can partially or completely determine the matters traditionally determined by teachers, such as establishing objectives, contents and schedules of learning, selecting learning methods and skills, self-supervising learning process, and self-testing learning effects. Autonomous learning is an ability of critical reflection, making decisions and independent action. Students basically play a dominant role in the process of autonomous learning. They master their studies and are responsible for their own learning content, learning pattern and learning speed. By doing so, on the one hand, they acquire knowledge and train their abilities to independently think and make decisions. On the other hand, they cultivate the consciousness of cooperation and innovation and become self-confident and proud. 


\section{Definition of autonomous learning}

Autonomous learning, as a personalized learning method, reflects the concept of constructivism that learners build up their own personal meanings based on existing knowledge. While emphasizing that learners play a dominant role in the learning process is an important thought of humanism psychology. Holec is the first to introduce the concept of autonomous learning into language learning in his work, Autonomy and Foreign Language Learning. In addition, he also defines learner autonomy as an ability being responsible for one's learning. Autonomous learning is mainly manifested in five aspects, including determining learning objectives, planning learning contents and schedules, selecting learning skills and strategies, supervising the learning processes and evaluating learning effects. Little thinks that autonomous learning is an ability of learners in "critical reflection, making decisions and independent action”[2]. Based on existing researches, Dam points out that autonomous learning not only depends on individuals but also groups[3]. Only through cooperating with others, learners can well acquire the ability of autonomous learning. Therefore, interaction, consultation and cooperation are important for learners to develop the ability of autonomous learning. Dickinson believes that autonomous learning is not only a learning attitude but also an ability to learn independently[4]. Benson thinks that the autonomy of language learning contains three aspects. First, autonomous learning is the behaviors and skills of independent learning. Second, autonomous learning is an internal psychic mobility guiding learners to study. Third, autonomous learning is to control the learning contents by oneself. Because of different research perspectives, western scholars give different meanings of autonomous learning. However, the cores of all the meanings emphasize learners' abilities of independent choice and adjustment, self-examination and cooperation in the learning process. In addition, we can conclude the main components, that is, attitudes, abilities and environments, of autonomous learning from different definitions. Attitude refers that learners are willing to adopt a positive attitude to study. Ability is the abilities and learning strategies that learners need to cultivate. While environment refers that learners should have lots of opportunities to train the autonomous learning ability.

\section{Training strategies for autonomous learning ability}

(1) Rebuilding learning consciousness and motivation

Consciousness and motivation are two important building elements of autonomous learning as well as important psychological factors restricting the study. Consciousnesses and motivation are essential factors in the cultivation of autonomous learning abilities. Learning motivation is an internal impetus for motivating, maintaining and promoting the learning activities of students. English learning motivation refers to the desires and motivations of students to learn English and presents learning conscientiousness and enthusiasm in the mental state of students. Thus, consciousness and motivation of autonomous learning depend on the internal impetus and confidence level of students as well as their levels of knowledge and skills. For undergraduates, they should fully realize that cultivation of autonomous learning ability mainly depends on themselves. Similarly, consolidating and improving English learning rely on their continuous language practices rather than only count on teachers in class. It is almost impossible for undergraduates to rebuild consciousness and motivation of English learning without intentional cultivation of teachers. In classroom teaching, teachers intensify the motivation of undergraduates according to their own factors, including hobbies and interests, English knowledge foundation, intellectual factors and cognitive competence. In addition, teachers need to help students to overcome their negative factors, including shyness, cowardice, anxiety and fear of failure. Moreover, in spare time, teachers should encourage students to actively take part in English club, listen to and watch English programs as well as communicate with foreign teachers boldly.

(2) Strengthening the efficacy sense of autonomous learning

Self-efficacy is the internal impetus and the precondition of autonomous learning and a crucial variable influencing the independent study of undergraduates. That is, self-efficacy has influences on students in setting of learning objects, self-regulatory process of learning and application of autonomous learning strategies. Researches of the pedagogy and the psychology show that different people have different independences. Independences can divide into field dependence and field independence according to their degrees. Students with high field dependence lack of learning initiatives and have a strong dependency. While those with strong independence present an independent and positive posture in the learning process (3). For learners themselves, fostering independent and positive personality traits is a necessary way to improve the efficacy sense of autonomous learning. Therefore, according to actual conditions, undergraduates can give play to the learning initiatives, play their dominant role and realize the self-construction for knowledge. Thus, 
students can change the field dependence, promote the field independence and improve the efficacy sense of autonomous learning.

(3) Supervising the service condition of learning strategies

Autonomous learning is the ability that learners control themselves to learn, involving setting learning objectives, self-supervising and self-evaluating. Autonomous learning not only requires students to have right learning attitude and active cognitive psychology, but also have various abilities, such as strong cognitive competence, predictive ability and speech analysis and judgment capability. All the aforementioned abilities can be summarized as the ability to flexibly apply learning strategies. Autonomous learning from the prospective of constructivism advocates the students-centered learning under teachers' guidance. It emphasizes students' dominant role in cognition and guiding function of teachers. Practice proves that self-regulated English learning of undergraduates cannot exist without teachers' guidance and supervisor, especially for the learning strategies. Learning strategies include vocabulary learning, reading and listening comprehension, translation, oral communication and writing skills. The training of learning strategies not only can improve learning effects and achieve learning objectives, but also can be helpful for students to explore a proper learning approach. For example, according to personal factors, such as learning goal, English basis and learning ability, one formulates detailed learning plan with strong operability (including specific time and learning contents). By doing so, they reach the purpose of self-government and decision in the learning process. Teachers should focus on supervising the service condition of learning strategies in the process of supervising the autonomous study of students in free time. Teachers need to encourage students to practice the learning strategies persistently as well as lead the students to consider how to use learning strategies effectively. Only by doing so, students can become independent and efficient learners in acquiring knowledge and learning management.

(4) Positive evaluation and correct attribution

In English learning, self-evaluation and the experience of active speech activities of students are the basis of continuously conducting English learning activities and acquiring more speech practice. In addition, they are also a power source of continuously adjusting and improving one's speech acts. The evaluation makes students clearly know their own study situations. Students can reschedule and adjust their study plans after learning their own grades and disparities with others. In this way, students become more active in the learning. However, due to long-term constraints by traditional education models and highlighting of exam-oriented education, autonomous learning abilities of undergraduates are unsatisfactory today. Evaluating learning process entirely by oneself tends to be difficult, so it still needs teachers to supervise and urge students to a great extent. For example, teachers supervise students' participation in network platform and carry out network on-line test. In addition, teachers should show the results of examination and evaluation to students in a proper way and then communicate with them. After finish the evaluation, more important thing is to strengthen the attribution training for students. That is also to say, teachers help students to build correct mindset and gradually establish a reasonable attribution model. Ascribing successes and failures to individuals' effort not only can improve the cognition of students on self-worth and autonomous learning ability, but also can inspire students' interests in English learning and learning duties. By doing so, students can overcome greater difficulties and be competent for tasks of future autonomous learning.

\section{Conclusion}

Autonomous learning is a kind of learning that learners master their learning by themselves. In addition, it is an ability that learners have to possess in the student-centered class. Considering the current situation of foreign language teaching in college, it should deepen the understanding of issues about the teaching and learning of foreign languages at present, especially the issue about the cultivation of learners' autonomous learning ability. This is because the final result of foreign language acquisition depends on the autonomous learning of learners themselves. Therefore, 
developing autonomous learning consciousness of foreign language learners has important guiding and practical significances for the foreign language learning reform in China. Additionally, the accomplishment of autonomous learning is a systematic project, which not only needs to change the guiding ideology of foreign language teaching, but also needs to dramatically change teaching environment, contents, methods, and so on.

\section{Acknowledgements}

This work is supported by Social Science Foundation of Liaoning Province (No. L15DWW005) and Bohai University Teaching Reform Project (No.BDJG15QNB002).

\section{References}

[1] H. Holec, Autonomy and Language Learning[M] . Oxford : Pergamen ,1981.

[2] D. Little, Learner Autonomy 1 : Definitions , Issues ,and Problems[M].Dublin : Authentik ,1991.

[3] L. Dam, Learner Autonomy 3 : From Theory to Classroom Practice[M].Dublin :Authentik ,1995.

[4 ] L. Dickinson, A. Wenden. Special Issue on Learner Autonomy[J ]. System 1995, 23(2). 